\title{
Research on Reform of Interpretation Course for English Majors in Private Colleges and Universities
}

\author{
$\mathrm{Bu}$ Xun \\ Shanghai Normal University Tianhua College. Shanghai 201815
}

\begin{abstract}
Restricted by some objective factors such as faculty structure, enrollment quality and so on, private colleges and universities experience some difficulties in making breakthrough in the interpretation course for English majors, achieving satisfactory teaching results and receiving encouraging feedback from employers. Based on demand analysis for the interpretation market and learner, and the enlightenment from Xiamen Interpretation Mode, the thesis regards the documentary research as clues, and suggests that private colleges and universities should set clear training target for interpreters, improve the curriculum system, upgrade interpreting teaching, prioritize cultivation of interpreting skills and emphasize the communicative feature of interpretation.
\end{abstract}

Keywords-Demand analysis; Curriculum; Skill-oriented; Interpreting teaching

\section{INTRODUCTION}

With the deepening of globalization and the improvement of China's international status, many global events and international conferences have been frequently held in China. As a result, these activities in foreign affairs give rise to increasing demand for interpreters. The training objectives for interpreters and translators have been proposed in Teaching Requirement For Undergraduate Students Majoring In Translation And Interpretation In Higher Education in 2012: "Translation and Interpretation for undergraduate students in higher education aim at training professional and general personnel with high moral standards and broad international perspective. Besides the basic language, graduates are supposed to acquire capability of logical thinking, broad knowledge, strong cross-cultural communicative competence and excellent professional ethics. In addition, except being familiar with social culture at home and abroad, and basic translation theory, they are also supposed to acquire some professional skills of translation and interpretation, use translation tools expertly, know the workflow of translation and other related industry, and have the strong ability of independently thinking, working and coordinating. And the graduate can complete the moderately difficult translation, interpretation and other cross-culture work in the area of foreign affairs, economy, trade, education, culture, science, technology and military." The curriculum of translation and interpretation for the undergraduate students was divided into three sections in The Teaching Requirement including knowledge of language, skills of translation and interpretation and other related knowledge, and the core courses have been made clear in each section. The student who has complete the regulated courses should acquire the following six abilities: bilingual knowledge and skills, bilingual transference, knowledge about computer aided translation, communication skills, professional ethics as a translator or interpreter, and the other related industrial knowledge [1].(He Yungeng, 2013)

Since the interpretation course became the compulsory one for English majors in universities in 2000, it has been in its highest pitch now. Being in line with the general trend, private colleges and universities are dedicated to training the application-oriented interpreters with comprehensive knowledge, hoping to meet the requirements of market for talents. However, private colleges and universities have its own restrictions on faculty and enrollment: first, the teachers for interpretation are supposed to have some practical experience because the interpretation teaching entails practical skills and real experience while most of the teachers for interpretation in private colleges and universities are nonprofessional ones most of whom major in linguistics or literature and have less practical experience in interpretation, which makes it impossible to share real practical experience in interpretation with their students; as to the teaching mode, teachers mainly uphold the traditional content-centered teaching philosophy: the course is classified into different topics, combined with trial-and-error practice, namely, students interpret one paragraph, the teacher provides feedback and demonstration before students reinterpret the same paragraph, through which the teaching effect is unsatisfactory. Also, English majors in private colleges and universities have relatively limited language ability and weak foundation; their motivation and self-learning ability are far from high; the teaching material of interpretation sold on market places more emphasis on the quality of language; besides, the content is much too challenging and the topics out of date, which is difficult to stimulate students' interest. At present, there are no interpretation teaching materials available that are tailored to English majors in private colleges. 


\section{THEORETICAL BASIS}

Demand analysis theory refers to some technologies and methods of research on need including self-examination, interview, observation and questionnaire and has been broadly applied into education. With the focus transformation from the language need of learner to the learning need of one in the teaching of foreign language, demand analysis begins to be applied into the area of general English teaching as the inevitable steps of foreign curriculum design [2](Chen Binging, 2009).

Demand analysis of interpreters' market can offer scientific evidence for the description of educational objectives, standards for professional interpreters, curriculum, teaching requirements, teacher cultivation, teaching principles, material, methods and skills, tests and evaluation, and can meet the demand of market for interpreters and selfdevelopment of students [3] (Zhuang Zhixiang, 2007). Undergraduate-level translation teaching should focus on the market demand [4] (Zhang Junyan, 2008); on the basis of status quo of translation and interpretation, and the demand for the professional translators and interpreters on the market, the training of interpreters and translators can be scientifically conducted on purpose [5](Mu Lei, 2012 ).

Teaching Requirements is the significant ground of setting translation and interpretation curriculum in universities while the curriculum is not linear and static. And different places have different demands for curriculum and with the passage of time, demand and condition of implementing the curriculum will also change. Therefore, it is necessary to make the intermittent and constant demand analysis, which can make sure that the developed curriculum does not drift off the course and meets the changing demand and the teaching objectives.

On the basis of demand analysis for translation market, Ren Yuehua proposed some thoughts and advice for the construction of curriculum in undergraduate level translation and interpretation and she made the market demand analysis according to the recruitment advertising of translation company [6]. Su Wei (2011) conducted research on the curriculum of consecutive interpreting of undergraduate level translation and interpretation in four universities in China under the perspective of learner' s demand and offered some advice for the upgrade of interpretation course system in inland. For instant, students hoped that the objective of interpretation course could be more specific and practical, the training of using Chinese could be increased into the content of course, the interpretation exercise after class could be guided by the teacher and more feedback hoped to be got after the curriculum evaluation [7]. Based on the questionnaire analysis and interview from undergraduate level translation and interpretation majors in two universities, Yao Lingyi and $\mathrm{Xu}$ Minjun (2015) did research on the self-demand and the status of translation and interpretation majors, and found that students had a relatively clear cognition about the basic condition of their own majors(for example curriculum) and abilities, but universities fail to provide sufficient course teaching and information, and students pay little attention to the improvement of their own ability, which cause trouble for students [8].

The translation teaching should keep in contact with the market and make reasonable adjustment in time according to learner's demand and change in society. The definition of translation teaching proposed by Canadian scholar, Delisle (1988) is widely accepted among the academic circles and he thought that the key point of translation was not to master language structure or enrich the linguistic knowledge, but to train the translators; and he advocated skill-oriented interpreting teaching [9].

As early as 1995, Gile suggested that comprehension process (C) was an interactive relationship between linguistic knowledge (KL), extra-curricular knowledge (ELK) and analysis (A) [10]. Based on this formula, Xiamen University has created its own interpretation teaching model and believes that there are three basic components in interpreting communicative behavior $(\mathrm{I})$ : understanding $(\mathrm{C})$, expression $(\mathrm{R})$ and analysis (A), skills and guidelines (P) play a crucial role in the training process. This model emphasizes the dynamic interaction between interpreting skills and linguistic knowledge, illocutionary knowledge, discourse analysis skills and intercultural communicative strategies. It proposes the important principle that interpreting training should focus on skills and professional training [11] (Chenjing, 1999). On this basis, Xiamen University further expanded the training process in 2008 by adding two modules, Interpretation Preparation (FB) (Language, Knowledge and Psychological Preparation) and Quality Control (QC) (Testing and Quality Assessment). The pedagogy based on skill training advocates guiding students to master interpreting skills rather than assessing interpreting products (Gile, 1995). Chen Jing (1999) proposed that interpreting teaching should first establish the basic skills involved in each stage, such as listening, refining, interpreting, presentation skills, interpreting notes, digital interpreting, discourse analysis, linguistic reorganization, intercultural communication analysis and coping strategies, then configure the appropriate material for practice and highlight the skill line in the exercise.

\section{ENLIGHTENMENT}

Private colleges and universities should intensify their function of serving for society, training applied and interdisciplinary talents and offering technologies and service that can meet the needs of regional economic and social development. Therefore, when the interpreting class is set up, it should make its position clear, create reasonable objectives, and stress the practicality and skill of interpretation so as to complement research universities and to achieve coordinated development. Specifically, the objectives of interpreting teaching of English majors in private colleges and universities are to enable students to acquire the process of and master the features of interpreting communication, and train their basic interpreting skills, thus qualifying them for lower-to-medium level of interpretation work, such as escort interpreting for foreign guests, exhibition interpretation and so on [12]. Based on the above training objectives, given the status quo of interpreting teaching in private colleges and demand analysis of interpretation market and learners, and inspired by Xiamen 
Interpretation Mode, the enlightenments on interpretation course in private colleges go as follows:

First, as for the construction of teaching staff, privately-run colleges and universities can implement the policy of "bringing in and going out". On the one hand, through the cooperation between school and enterprise, we can sign agreements with each other for mutual recruitment and mutual employment so that we can actively introduce dual-qualified teachers who are experienced in interpretation and practical experience. On the other hand, through the industryuniversity-research project, teachers who lack experience in interpretation go out, study on post and work on post to accumulate more hands-on interpreting experience and classroom materials.

Second, in view of the quality of students in private colleges and universities, teachers can exert more painstaking efforts on the selection of materials and teaching activities in the classroom. For example, teachers may choose some interesting and time-sensitive articles to stimulate students 'interest and enhance students' confidence by reducing the difficulty, such as truncating and slowing down the material with bilingual subtitles. For some popular video materials, teachers can send the text to students in advance to preview, or provide the corresponding Chinese video, so that students understand the relevant background information. Focusing on the goal of cultivating students' basic interpreting skills, teachers can design a wide variety of teaching activities such as reading pictures, story series, contrastive analysis of different translations, and rehearsing based on key words to create an active classroom atmosphere. In addition, in the classroom, we can provide the students timely and effective feedback through the interactive comments of Chinese and foreign teachers so as to realize the micro-monitoring of language and the macro-monitoring of communicative effect. Through the mutual peer assessment between students and students' self-reflection, students can enhance their awareness and self-learning ability, thus feeling their own progress.

Thirdly, in light of the practicality of interpreting courses, in order to improve students' practical ability, interpreting teaching should also be devoted to the integration of classrooms and workplaces to simulate a variety of interpreting scenes. According to Gile, simulation and Role Play are effective teaching methods for interpreting. By inviting experts from all fields into the classroom to set up realistic audience scenarios, students can feel the tension in the interpreter's field as well as their ability to cope. Schools should also devote their efforts to liaising with foreign affairs agencies and convention centers to provide more opportunities for interpreters to practice, including contacting guests, attending assistants, observing the scenes, obtaining background information, communicating customer needs and working with professional translators so that students can learn to apply their theoretical expertise to practice.

\section{CONCLUSION}

Private colleges and universities are an inevitable part of China's higher education and have strong functions of serving for society. Based on the status quo of faculty structure and enrollment quality in private college, its interpretation teaching should firmly focus on training basic interpreting skills of students, regard the market demand as the guide, improve the curriculum continuously, upgrade the teaching, establish the connection between colleges and enterprises, and make full use of the translation practice base to train the translation talents with multiple qualifications to adapt to social and economic development.

\section{REFERENCES}

[1] He Xuegeng, Zeng Yanbo. The Current Situation and System Reconstruction of Textbook Translation Courses in Colleges and Universities [J]. Journal of PLA University of Foreign Languages, 2013, (5):69-72

[2] Chen Bingbing. A Summary of Foreign Demand Analysis [J]. Foreign Language Teaching and Research, 2009,(3): 125-130

[3] Zhuang Zhixiang. On the Construction of Translation Specialty in China [J]. Foreign language, 2007,(3): 14-23

[4] Zhang Junyan. Undergraduate teaching of translation should be guided by market demand [J]. Journal of Suzhou Institute of Education, 2008, (4):114-116

[5] Mulei, Yang Dongmei. From the status of the translation enterprises and the market demand to see the professional training of translators $[\mathrm{J}]$. Foreign Language and Foreign Language Teaching, 2012,(3):57-60

[6] Ren Yuehua. Enlightenment of Social Needs on the Setting of Undergraduate Courses for Translation and Translation [J]. Journal of Guangdong Polytechnic Normal University, 2009,(2):109-111

[7] Su Wei. An Investigation and Analysis of Demands for Interpretation Courses from the Perspective of Learners [J]. Foreign language session, 2011,(5):84-92

[8] Yao Lingyi, $\mathrm{Xu}$ Minjun. Investigation and Thoughts on Self Positioning of English Translation Majors [J]. Higher education, 2015, (3):107-109

[9] Jean delle. Translation Theory and Translation Teaching Method [M]. Sun Huishuang, translator. Beijing: International Culture Publishing Company, 1988:24-26

[10] Gile, D. Basic Concepts and Models for Interpreter and Translator Training [M]. John Benjamins Publishing Company, 1995.

[11] Chen Jing, Dynamic Research on Interpretation and Preparation of Interpreting Textbooks [J], Foreign language community 1999(4):44-48.

[12] Wu Zhong, Li Lihua, Wang Wei. Orientation and Strategy of English Majors' Interpreting Teaching in Independent Colleges [J]. Journal of Yangtze University (Social Science Edition), 2011(3):97-98. 